Published in proceedings of the Academy of Management Conference Annual

Meeting 2015, Vancouver, Canada, 7-11 august 2015, which should be cited to refer to this work.

12060

\title{
The Poor Man's Guide to Paradox: Managing Dualities in Corporate Turnarounds
}

\begin{abstract}
Since organizational scholars argue that resource scarcity accentuates dualities’ oppositional and relational nature, we need to know more about whether and how resource-scarce firms can manage paradox. Based on a longitudinal study of 107 Central European turnaround initiatives, we find empirical evidence that even resource-scarce organizations can successfully manage dualities. However, these organizations’ approaches to paradox resolution differ markedly from those previously described for organizations with abundant resources. Successful turnaround companies manage the duality between retrenchment and recovery by maintaining a biased balance within each stage of the turnaround process: while they combine the two activities, they concentrate on the most salient issues by focusing more on one activity than the other. Furthermore, they pursue a shifting balance throughout the turnaround process: while the retrenchment-recovery balance is biased towards retrenchment in the initial stage, the bias shifts towards recovery in the advanced stage. Scarce resources are thus targeted at addressing the most urgent needs at different points in time. Based on these findings, we contribute to the organizational paradox literature by developing a process perspective for managing dualities that integrates the synergistic combination and temporal separation strategies to addressing paradoxical tensions.
\end{abstract}

\section{Keywords:}

Corporate turnaround; dualities; organizational paradox; recovery; retrenchment 


\section{Introduction}

Organizations are confronted with various paradoxical tensions such as those between stability and change (Leana \& Barry, 2000), mechanistic and organic structures (Burns \& Stalker, 1961), centralization and decentralization (Siggelkow \& Levinthal, 2003), and exploration and exploitation (March, 1991). Paradoxes can be understood as "contradictory yet interrelated elements (...) that seem logical in isolation but absurd and irrational when appearing simultaneously” (Lewis, 2000: 760). Paradox as a meta-theory (Lewis \& Smith, 2014) seeks managerial strategies that can support contrasting elements and benefit of constructive tensions between multiple divergent demands (Evans, 1999; Farjoun, 2010; Lewis, 2000).

While early paradox scholars often conceptualized paradoxes as dualisms requiring temporal or spatial separation between the contradictory elements (e.g., Cameron, 1986), more recent research generally suggests that paradoxes are dualities that demand synergistic combination (Farjoun, 2010; Smith \& Lewis, 2011). However, simultaneous attention to opposing elements consumes substantial financial and managerial resources (Gupta, Smith, \& Shalley, 2006). Managing dualities is thus difficult for resource-scare organizations: the scarcer the resources, the greater the likelihood that the opposing elements are mutually exclusive. Scarcity causes latent tensions to become salient, which means that the dualities' oppositional nature is accentuated further (Smith \& Tushman, 2005). To date, little is known about how organizations manage dualities (Smith \& Lewis, 2011) and even less about how resource-scarce organizations take on this challenge (Raisch \& Birkinshaw, 2008).

Corporate turnarounds - defined as a firm's economic recovery of a survival-threatening decline situation (Robbins \& Pearce, 1992) - provide a unique context to explore these questions. A firm facing a turnaround situation experiences a resource loss sufficient to 
compromise its viability (Arogyaswamy, Barker, \& Yasai-Ardekani, 1995; Pajunen, 2006). The scarcity may even go beyond financial resources since turnaround situations often prompt the exodus of a firm's most capable managers (Chen \& Hambrick, 2012). Prior research describes the tensions between retrenchment - increasing efficiency through cost and asset reductions and recovery - improving a firm's market position through strategic change and innovation during corporate turnarounds (Barker \& Duhaime, 1997). Taking a duality perspective, Schmitt and Raisch (2013) recently found that turnaround firms that combine the two activities benefit from higher turnaround performance. However, these authors did not address how these resource-scarce organizations manage the duality of retrenchment and recovery.

In this study, we argue that two managerial strategies can enable turnaround firms to successfully combine opposing activities despite of their resource limitations. First, turnaround firms can maintain a biased balance within each stage of the turnaround process: while they combine retrenchment and recovery, they concentrate on the most salient issues by focusing more on one activity than the other. This allows them to benefit from the interrelations between the opposing elements, while being less exposed to the costs associated with managing their contradictions. Second, turnaround firms can pursue a shifting balance throughout the turnaround process: while the retrenchment-recovery balance is biased towards retrenchment in the initial stage, the bias shifts towards recovery in the advanced stage. This shifting balance allows turnaround companies to minimize resource consumption by better aligning their activities with the varying requirements over time. Based on a longitudinal study of 107 Central European turnarounds, we find that turnaround firms relying on these two managerial approaches - biased balance and shifting balance - benefit of the highest turnaround performance. 
We use these findings to contribute to the organizational paradox literature. Our main contribution is the development of a stage perspective for managing dualities that integrates the temporal separation and synergistic combination strategies to addressing paradoxical tensions. This contribution expands prior theorizing on paradoxes along two dimensions. First, while the prior literature has presented synergistic combination and temporal separation as opposed, alternative solutions (e.g., Poole \& Van de Ven, 1989), we provide theoretical arguments and empirical evidence that a synthesis (Farjoun, 2010), which combines the two approaches' positive elements while minimizing their negative effects, is possible and particularly beneficial for resource-scarce organizations. Second, prior paradox studies have been frequently criticized for their static, cross-sectional perspectives (e.g., Smith \& Lewis, 2011), which may oversimplify the complex nature of paradoxical tensions and their management (Schad, Lewis, \& Raisch, forthcoming; Smith 2014). Our stage perspective distinguishes different turnaround phases and highlights transitions in managing organizational dualities.

\section{Dualities and Organizational Resources}

From a paradox perspective, long-term firm survival and prosperity require continuous efforts to meet multiple, divergent demands (Cameron, 1986; Poole \& Van de Ven, 1989). In line with prior studies (Clegg, Viera de Cunha, \& Cunha, 2002; Lewis, 2000; Smith \& Lewis, 2011), we define paradoxes as contradictory, yet interrelated, elements that exist simultaneously and persist over time. Such elements seem incontestable when considered in isolation, but inconsistent or even absurd when juxtaposed (Van de Ven \& Poole, 1988). Exploring theoretical opposites through a paradox lens has the potential to unfold new, encompassing organizational theories (Eisenhardt, 2000; Lewis, 2000). 
Initially, paradox scholars tended to accentuate the contradictions between opposing poles, suggesting that organizations take measures to separate the contradictory elements (e.g., Cameron, 1986). One way of managing these "dualisms" (Farjoun, 2010) is to pursue the inherently conflicting elements in structurally separate domains (O'Reilly \& Tushman, 2008; Raisch, 2008). Alternatively, the tensions can be managed sequentially, by first emphasizing one aspect of the tension and then the other (e.g., Burgelman, 2002). For instance, Jarzabkowski et al. (2013) propose a time-based approach to manage dualism’s cycles of tensions and responses.

More recently, paradox research has shifted its primary attention to an alternative perspective in which the contrasting elements are seen as conceptually distinct, but fundamentally interdependent (Farjoun, 2010). Such dualities are synergistic and interwoven polarities that are both contradictory and complementary. Attaining one type of outcome requires some elements of the other (Andriopoulos \& Lewis, 2009). The interwoven nature of these dualities casts doubt on organizations’ ability to neatly separate the opposing elements. Hence, the harmonizing of contradictory, yet interdependent, opposites becomes important rather than segregated efforts targeted at one or the other (Chae \& Bloodgood, 2006; He \& Wong, 2004).

Given the increasing uncertainty and turbulence of today's business environments, dualities undoubtedly provide a powerful framework with which to explore the complexity of current organizational and managerial challenges (e.g., Besharov \& Smith, 2014). However, research on dualities is scarce and the few extant studies point to the importance of resource abundance to manage them. Given that resource allocation decisions carry substantial and symbolic value as they display managerial and strategic choice (Bower \& Gilbert, 2005), Smith (2014) recently emphasized the allocation of scarce financial, human, and managerial resources as manifested outcomes of organizational dilemmas. The limited availability of organizational resources decreases the organization's flexibility since it demands managerial resource allocation decisions that make choices between opposing elements. Gupta et al. (2006) argue that resource scarcity 
can cause latent tensions to become salient, which means that the oppositional and relational nature of dualities is accentuated further. When leaders decide how to allocate human or financial resources, scarcity exacerbates the tensions between opposing and interdependent alternatives (Smith, Binns, \& Tushman, 2010; Smith \& Tushman, 2005).

When facing competing tensions of allocating scarce resources, leaders can attempt to ignore, compartmentalize, aggregate, or synthesize these paradoxical demands (Kraatz \& Block, 2008). Additionally, leaders are confronted with inertial tendencies stemming from existing organization design (Henderson \& Clark, 1990), routines (Gilbert, 2005), and competencies (Leonard-Barton, 1992) that emphasize an existing strategic domain over a new one. As a result, such leaders and organizations may be more prone to split interwoven elements into either/or decisions (Smith, 2014), blurring their interrelatedness, which may lead to negative performance consequences (Smith \& Lewis, 2011).

Conversely, in a recent study of corporate turnarounds, Schmitt and Raisch (2013) provide first empirical evidence for the beneficial role of integrating contradictory elements in situations of severe resource scarcity. However, the authors highlight the need for further research on how resource-scarce organizations achieve this duality and point to situations in which organizations may be forced "to opt for moderate levels of [...] the two opposing elements" (Schmitt \& Raisch, 2013: 1240). The paradox literature thus needs further conceptual work and empirical validation of resource scarcity’s role for dualities. Developing an understanding of how organizations can manage dualities under these conditions responds to recent calls to further clarify paradoxical tensions, their management, and their impact on organizations (e.g., Smith \& Lewis, 2011).

\section{The Duality Between Retrenchment and Recovery}

We focus on turnaround situations in which organizations sustain "resource losses that will cause the firm to fail if unabated” (Arogyaswamy et al., 1995: 497). Turnaround firms are faced 
with the paradoxical challenge between increasing operational efficiency to ensure financial stability and sustainably reposition the firm through strategic change (Bibeault, 1982). Scholars have compared this challenge to the exploitation-exploration duality (Lohrke, Ahlstrom, \& Bruton, 2012; Walrave, van Oorschot, \& Romme, 2011). We thus consider the turnaround context as particularly appropriate to study how firms under resource scarcity manage dualities.

Corporate turnarounds characterize situations in which firms economically recover after experiencing a survival-threatening performance decline (Boyne \& Meier, 2009; Hofer, 1980; Trahms, Ndofor, \& Sirmon, 2013). Scholars have explored a range of turnaround activities that are categorized into two distinct sets of activities: retrenchment and recovery (Robbins \& Pearce, 1992). While retrenchment activities focus on increasing a firm’s efficiency through cost and asset reductions (Lim, Celly, Morse, \& Rowe, 2013; Morrow, Johnson, \& Busenitz, 2004), recovery activities concentrate on improving its market position through strategic change (Barker \& Duhaime, 1997). The two activities are perceived as complementary rather than mutually exclusive turnaround strategies (Arogyaswamy et al., 1995). Hence, researchers have argued that turnaround success is less a function of whether firms opt for retrenchment or recovery, but depends on how these activities are combined during corporate turnarounds (Hoffman, 1989).

Prior turnaround scholars have generally described a sequential process in which firms initially engage exclusively in retrenchment, and then switch entirely to recovery activities (e.g., Filatotchev \& Toms, 2006; Lohrke et al., 2012; Pearce \& Robbins, 2008). Conversely, Schmitt and Raisch (2013) have recently argued that retrenchment and recovery are contradictory, yet interrelated, elements of corporate turnarounds that exist simultaneously and persist over time. Viewed as a duality, retrenchment and recovery, while conceptually distinct, are interdependent and mutually enabling activities. The authors found empirical evidence that turnaround organizations that combine the two activities have higher turnaround performance. 
Building upon Farjoun's (2010) comprehensive model of dualities, Figure 1 presents four relationships between retrenchment and recovery during corporate turnarounds. Quadrants 2 and 3 illustrate that retrenchment and recovery are interdependent, presenting retrenchment as an outcome of recovery (Q2) and recovery as an outcome of retrenchment (Q3). Quadrants 1 and 4 recognize the contradictions between retrenchment and recovery, showing how retrenchment (Q1) and recovery (Q4) support similar types of outcomes but undermine opposing ones.

Insert Figure 1 about here

First, we argue that recovery activities enable retrenchment activities (Q2). The resource scarcity condition requires turnaround firms to initially engage in retrenchment to avoid a further depletion of their resources, and to generate the resources required for recovery (Bruton, Ahlstrom, \& Wan, 2003; Castrogiovanni \& Bruton, 2000). In order to successfully retrench, turnaround firms need to know which resources are misaligned and which resources will be needed later on to implement the selected recovery strategy (Arogyaswamy et al., 1995). Additionally, interdependencies arise from the need for recovery activities to mobilize initial stakeholder support (Pajunen, 2006) and employee commitment to retrenchment (Schmitt, Borzillo, \& Probst, 2012). More recent turnaround research thus emphasizes the need for coherence between retrenchment and recovery activities and argues that recovery provides retrenchment with direction (Lohrke et al., 2012; Morrow et al., 2004; Trahms et al., 2013).

Second, further interrelations arise from retrenchment's enabling role for recovery (Q3). Given that recovery strategies consist of a long series of repeated changes (Morrow, Sirmon, Hitt, \& Holcomb, 2007), which constantly consume resources (Barker \& Duhaime, 1997), retrenchment plays an important role throughout the turnaround process as a resource provider for recovery activities (Castrogiovanni \& Bruton, 2000). Moreover, retrenchment creates the 
momentum and confidence for recovery moves since stakeholders' observation of quick improvements spurs motivation for future turnaround efforts (Khandwalla, 1983). Retrenchment may thus be essential to realize early successes that help build confidence, boost morale, and create the momentum required to implement recovery moves.

Third, contradictions between retrenchment and recovery arise because an emphasis on retrenchment tends to push turnaround organizations towards further efficiency measures along the same trajectory, while effectively undermining recovery activities (Q1). The literature refers to a 'mechanistic shift' in turnaround organizations, characterized by centralization of decision making and conservation of resources (Barker \& Mone, 1998; Musteen, Liang, \& Barker, 2011; Staw, Sandelands, \& Dutton, 1981). In such organizational contexts, managers tend to emphasize short-term cash flows and accounting returns, while reducing or postponing longterm investments in innovation (Hitt, Hoskisson, Johnson, \& Moesel, 1996). Moreover, a focus on retrenchment further exacerbates the deterioration in the firm's climate and decision processes (Arogyaswamy et al., 1995; O'Neill, 1986). Pursuing retrenchment can thus lead to a self-reinforcing cycle that suppresses rather than enabling recovery activities.

Finally, contradictions arise also from recovery's tendency to support further recovery, while undermining retrenchment (Q4). Turnaround research found that a focus on recovery is accompanied by an 'organic shift' characterized by high levels of decentralization, strong employee involvement, and increased organizational flexibility, which foster recovery, but may be less appropriate for retrenchment (Arogyaswamy et al., 1995). For example, Lohrke et al. (2012) describe how these contexts further reinforce the focus on new product exploration. 


\section{Managing the Duality between Retrenchment and Recovery}

As argued above, retrenchment and recovery are interrelated, yet contradictory, elements of corporate turnarounds that exist simultaneously and persist throughout the entire turnaround process. While the interrelations motivate the combined pursuit of retrenchment and recovery, the contradictions between the two activities suggest a clear focus on one or the other activity within each turnaround stage. How can resource-scarce companies in turnaround situations address this duality? The managerial challenge is to combine both types of turnaround activities in a way that allows for benefitting from their mutually enabling effects while effectively protecting the organization from their mutually harmful consequences. In line with previous studies (Barker \& Duhaime, 1997; Robbins \& Pearce, 1992; Trahms et al., 2013), we analyze these questions in the context of a two-stage turnaround process.

\section{Initial Stage: The Retrenchment Bias}

In the initial turnaround stage, the resource scarcity condition requires turnaround firms to engage in retrenchment to stabilize operations and generate the resources required for recovery (Bruton et al., 2003; Castrogiovanni \& Bruton, 2000; Robbins \& Pearce, 1992). Simultaneously, firms need to actively address their misalignment with the environment's realities (Pajunen, 2005). This requires recovery activities to identify the misaligned resources that the retrenchment activities should target (Lim et al., 2013; Morrow et al., 2004). Turnaround initiatives should thus combine retrenchment and recovery in this stage.

Since retrenchment and recovery compete for scarce financial and managerial resources (e.g., Sheppard \& Chowdhury, 2005), the two activities cannot be maximized at the same time. In successful turnaround firms, we thus expect an initial combination of retrenchment and recovery, but with a clear bias towards retrenchment. The level of retrenchment has to be high to ensure that enough resources are freed up to not only stabilize operations, but to also generate 
additional slack resources to enable subsequent, stronger recovery activities (Mone, McKinley, \& Barker, 1998; Robbins \& Pearce, 1992). Conversely, a too strong initial engagement in recovery may be harmful. The successful implementation of recovery activities is contingent upon the availability of abundant resources (Barker \& Duhaime, 1997). Using the declining firm's scarce resources for extensive initial recovery activities risks depleting these resources even more, which can increase organizational rigidity and lead to managerial paralysis (Musteen et al., 2011; Staw et al., 1981). Dedicating substantial resources to recovery may thus create a vicious cycle: the recovery activities consume scarce resources (such as managerial attention and financial assets), which leads to a lack of resources for retrenchment. As the retrenchment activities deteriorate, fewer committed resources are transformed into uncommitted resources, which in turn, further reduces the amount of resources available for recovery activities.

In sum, while both retrenchment and recovery are required in the initial turnaround stage, turnaround firms have to focus more strongly on retrenchment. Some initial attention to recovery is required to focus the retrenchment activities and ensure stakeholder support. Too much initial attention to recovery, however, may have adverse effects on a firm's ability to successfully manage the turnaround process. We thus suggest that a retrenchment bias - which combines a higher level of retrenchment activities with a lower level of recovery activities - is positively related to turnaround performance in the initial stage of the turnaround process.

Hypothesis 1: In the initial turnaround stage, a bias in the retrenchment-recovery balance towards retrenchment is positively related to turnaround performance.

\section{Advanced Stage: The Recovery Bias}

In the advanced turnaround stage, recovery activities are required to address the true causes of the decline and enable strategic change (Lohrke et al., 2012; Morrow et al., 2007; Robbins \& Pearce, 1992). Simultaneously, retrenchment activities are needed to maintain high levels of 
organizational slack and realize short-term successes to motivate stakeholders, both of which are vital conditions for sustained recovery (Barker \& Duhaime, 1997; Khandwalla, 1983). Corporate turnaround initiatives should thus combine retrenchment and recovery in this stage.

Since recovery and retrenchment make contradictory demands on the alignment of organizational resources (e.g., Chowdhury, 2002; Schmitt \& Raisch, 2013), we argue that the two activities have to be carefully balanced. In successful turnaround companies, we expect a combination of retrenchment and recovery in the advanced stage, but with a clear bias towards recovery. Strong recovery is essential for success because efficiency-oriented retrenchment activities will not solve the deficiencies in a declining firm's strategic orientation (Barker \& Duhaime, 1997), nor will they realign the firm with the evolving environment's demands (Morrow et al., 2007). Conversely, too strong retrenchment in the advanced phase may push the firm towards further efficiency measures along the same trajectory (Barker \& Mone, 1998). High levels of retrenchment have been related to a mechanistic shift in organizations, characterized by an increase in top management involvement in decision procedures, restricted information processing, and tight resource control (e.g., Staw et al., 1981). Since such an organizational context harms strategic change (Gilbert, 2005), the retrenchment efforts have to be limited.

In sum, retrenchment activities have to enable, not hinder, recovery activities in the advanced turnaround stage. Turnaround firms have to focus more strongly on recovery to resolve their strategic issues. While some attention to retrenchment is required, too much attention has an adverse effect on the firm's ability to successfully manage turnarounds. We thus suggest that a recovery bias - which combines a higher level of recovery with a lower level of retrenchment is positively related to turnaround performance in the advanced turnaround stage.

Hypothesis 2: In the advanced turnaround stage, a bias in the retrenchment-recovery balance towards recovery is positively related to turnaround performance. 


\section{Turnaround Process: The Shifting Balance}

The above arguments imply a shift from a retrenchment bias in the initial turnaround stage to a recovery bias in the advanced turnaround stage. The most obvious explanation for this shift is that it occurs after the initial retrenchment has successfully stabilized the organization and sufficient resources have been generated for recovery (Bruton et al., 2003; Filatotchev \& Toms, 2006; Robbins \& Pearce, 1992). While retrenchment activities are more important under the initial resource scarcity conditions (Barker \& Mone, 1998; Musteen et al., 2011), the increased availability of slack resources in the advanced stage should increase the likelihood of strategic change (Barker \& Duhaime, 1997; Grinyer, Mayes, \& McKiernan, 1988). Robbins and Pearce (1992) mention a "decision point" at the end of the initial stage, which allows decision makers to agree upon the measures to take in the advanced stage.

We build upon these arguments, but suggest that the shift may often go well beyond simple resource allocation decisions. As described above, the strong engagement in retrenchment in the initial phase tends to encourage a mechanistic tendency that enables further retrenchment, but effectively hinders more extensive recovery activities. Overcoming these obstacles to recovery may require substantial and conscious actions, such as changes to the top management team composition and/or the alignment of the organizational context (Arogyaswamy et al., 1995; Chen \& Hambrick, 2012). Aligning the leadership and organization with recovery implies that the primary attention shifts away from retrenchment and allows a stronger consideration of recovery activities. Rather than a gradual evolution of the retrenchment-recovery balance over time, we thus expect a formal shift from a retrenchment bias in the initial turnaround stage to a recovery bias in the advanced turnaround stage. Since this shifting balance allows turnaround firms to provide appropriate levels of retrenchment and recovery at different stages of the turnaround process, which represents perfect resource allocation and thus minimum waste of scarce resources, we expect it to be related to the strongest turnaround performance. 
Hypothesis 3: A shift in the retrenchment-recovery balance from a retrenchment bias in the initial turnaround stage to a recovery bias in the advanced stage is related to the highest turnaround performance.

\section{Methods}

We selected a research setting that addresses prior corporate turnaround studies' limitations. First, we collected primary data on turnaround initiatives to avoid most previous turnaround studies' reliance on archival data. Despite certain risks regarding reporting bias, several authors (Brush \& Vanderwerf, 1992; Dess \& Robinson, 1984) recommend using firm self-appraisal measures to obtain more fine-grained data and increase data reliability. Second, we collected field data on both public and private companies as these firms face different challenges during corporate turnarounds (Boyne \& Meier, 2009). Finally, we used turnaround consultants as informants to address prior studies’ problems with respondent subjectivity, a lack of response, and a small sample size (Chowdhury, 2002; Whetten, 1980). Turnaround consultants are particularly resourceful informants as they (1) contribute their rich expertise to managerial decision-making (Bergh \& Gibbons, 2011), (2) can benchmark their assessment with prior experiences and are less emotionally biased regarding performance outcomes (Zollo \& Meier, 2008), and (3) are more accessible when compared to turnaround managers who face the risk of civil and criminal liabilities.

Given varying legal constraints during turnarounds, we focused on Central European (Austria, Germany, and Switzerland) companies in distress. In this region, corporate turnarounds happen in two ways: out-of-court turnarounds and in-court bankruptcy proceedings (Davydenko \& Franks, 2008). Out-of-court turnarounds are used if firms have a chance of long-term survival and the troubled firm's main bank takes responsibility for monitoring the firm's turnaround attempt. The banks generally rely on external consultants' expertise and advice in order to limit 
their legal responsibilities in case of insolvency. Turnaround consultants are thus involved in practically every turnaround initiative.

The sample is generated via the three countries’ national consultant databases (maintained by the Austrian Federal Economic Chamber, the Association of German Consultants, and the Association of Swiss Consultants) that provide official contact information on consulting firms active in specific domains such as "turnaround." After consulting each turnaround consulting firms’ website and discussions with industry experts, we confirmed a total population of 136 Central European turnaround consulting firms (38 Austrian, 75 German, and 23 Swiss). We approached the 136 firms’ main contact person for turnaround services by email of which 27 emails were undeliverable. Of the remaining 109 firms, 33 firms (30.3\%) agreed to participate in our study. T-tests on size and scale (Bergh \& Gibbons, 2011) showed no significant differences between the participating and non-participating firms. These 33 consulting firms reflect well the European consulting industry’s structure due to its mix of large (27.3\%), medium-sized (21.2\%), and small (51.5\%) firms. Overall, our sample included 12 Austrian, 14 German, and 7 Swiss turnaround consulting firms.

In phone interviews with the participating firms' main contact persons, we explained the study’s interest in analyzing out-of-court turnaround initiatives initiated between 2003 and 2004. We also emphasized the importance that the consulting firm had been engaged throughout the project, and that the turnaround had had to be completed at the time of inquiry. While this approach excluded firms whose turnaround initiatives failed in the process, it matches our main research interests of exploring interrelated turnaround activities throughout the entire turnaround process and analyzing how these activities relate to relative differences in turnaround performance. To be considered as a turnaround initiative, we respected established criteria in the 
turnaround literature: a four-year period comprising two years of positive ROI and then two years of an average pretax ROI below 10\% (Barker \& Mone, 1994), the presence of negative cash flow, a negative ROA, and an absolute and relative-to-industry decline over two years. Our main contact persons identified 121 turnaround initiatives that fulfilled these criteria.

Subsequently, we asked our main contact person to identify one supervised consultant from each of the 121 turnaround initiatives. Given the hierarchical structure in consulting companies (Bergh \& Gibbons, 2011), we focused on project managers with at least two years' experience of executing, managing, and planning turnaround projects prior to our inquiry. Our main contact persons sent our questionnaire to 121 distinct consultants of whom 75 responded immediately. By instigating follow-up phone calls, we managed to obtain the remaining 46 questionnaires. We excluded 14 questionnaires due to incompleteness or insufficient informant competency. The final sample of 107 responses includes 27 Austrian (25.2\%), 64 German (59.8\%), and 16 Swiss (15.0\%) turnaround initiatives of which 28 occurred in public (26.2\%) and 79 in private companies (73.8\%). The majority of these turnaround initiatives (72) had been conducted in the manufacturing industry (67.3\%), while the remainder (35) had occurred in service industries (32.7\%). Environmental conditions of each turnaround attempt varied with 16 turnaround initiatives (15.0\%) in growing industry, 79 in mature industry (73.8\%), and 12 initiatives in declining industry environments (11.2\%). On average, the firms employed 1,210 people.

To control for potential informant biases (Huber \& Power, 1985), we assured the key informants' competence (consultants had an average consulting experience of 8.8 years and tenure of 5.9 years), outlined the benefits of our study, offered to share the study's results, and pre-tested our questionnaire to ensure clarity. We also minimized concerns about retrospective data collection and found no significant difference between the responses of those who had 
returned our questionnaire immediately and late. Given that consulting firms constantly document their turnaround efforts to limit their legal responsibility, we believe that retrospective bias has been minimized. To minimize concerns about self-selection bias, we searched the Bloomberg $^{\circledR}$ database and identified 36 firms in distress and compared them to our sample companies. The comparison group's firm-specific characteristics showed no significant differences with our participating firms in terms of their total assets $(p=.31)$, employees $(p=.51)$, sales ( $p=.33)$, and ROA ( $p=.23)$. Finally, we reduced concerns about common method bias by asking the consultants to provide data for the independent variables, while the supervisors provided data for the dependent variables.

\section{Measurements}

Turnaround stages. Researchers commonly measure turnaround activities at two points in time, namely the worst financial year and the first year of performance improvement (Pearce \& Robbins, 1993). However, Pearce and Robbins (1993) point out that this could limit the identification of distinct stages. They suggest including an intermediate observation point. We followed their suggestion and pre-defined two process stages. We defined the initial stage as lasting from the beginning of the turnaround project until the year of the sharpest absolute performance decline in ROI (Robbins \& Pearce, 1992). We defined the period from this transition point to the end of the project as the advanced stage.

Dependent variable. In line with prior research’s suggestions (e.g., Dess \& Robinson, 1984; Powell, 1992), five subjective measures $(\alpha=.94)$ based on prior turnaround research (Morrow et al., 2004; Robbins \& Pearce, 1992) were used to assess the turnaround initiative's overall performance. Respondents indicated the relative-to-industry net change of the turnaround firm's performance according to (1) sales, (2) market share, (3) ROI and (4) ROA. As suggested by 
Datta (1991), respondents additionally provided their (5) individual opinion about the firm's overall performance improvement during the corporate turnaround.

Independent variables. Based on Michael and Robbins’s (1998) suggestions, we measured the retrenchment activities based on a Likert-type response scale (ranging from 1: 'given low priority’ to 7: 'given high priority’) for each turnaround stage ('initial stage’ / 'advanced stage': $\alpha=.86 / .86$ ). These measures included: (1) the reduction in the finished goods and inventory, (2) employee layoffs, (3) the reduction in maintenance costs, (4) the reduction in property, plants, and equipment, (5) the reduction in marketing costs, and (6) the reduction in R\&D expenditures. Similarly, the recovery activities were measured through five items ('initial stage' / 'advanced stage': $\alpha=.85 / .86$ ) based on the following measures adapted from Robbins and Pearce (1992): (1) new markets, (2) new product or service offerings, (3) new production or service processes, (4) new competitive advantages, and (5) new organizational structures.

Control variables. Several control variables reduced the likelihood for potential misinterpretations of the study's dependent and independent variables. First, prior studies have argued that a firm's turnaround strategy is dependent on the firm's severity of decline (Hofer, 1980). The variable “severity of decline” thus assessed the firm’s level of available slack (Chen \& Hambrick, 2012; McClelland, Liang, \& Barker, 2010) by using the quick ratio ([current assets - inventory]/current liabilities) and the leverage ratio ([total debt/total assets] x 100). Second, external and internal causes of decline (Filatotchev \& Toms, 2006; Pajunen, 2006) have been argued to influence the selection of turnaround activities (e.g., Barker \& Duhaime, 1997). Consequently, the variable cause of decline used Robbins and Pearce's (1992) seven-point scale (ranging from 1: 'completely insignificant' to 7: 'greatest significance') measured the relative impact of four external causes (economic problems, competitive change, technological change, social change) and four internal causes (lack of operating controls, overexpansion, excessive leverage, top management). Given that firm size can influence turnaround firms' ability to 
implement different turnaround strategies and performance (e.g., Bruton et al., 2003), the third type of control variable firm size assessed the natural logarithm of the firm's total number of employees to correct skewed distributions (McClelland et al., 2010). Fourth, recent turnaround research (Ndofor, Vanevenhoven, \& Barker, 2013) postulates a relationship between industry environment and turnaround performance. The variable industry environment thus controlled for the main industries' average market growth rate over the six years prior to the turnaround (Morrow et al., 2004). This control variable was coded '0’ to indicate growth industries (> 10\% average market growth rate), ' 1 ' to indicate mature industries ( $0-10 \%)$, and ' 2 ' to indicate declining industries $(<0 \%)$. Finally, a dummy variable consulting firm assessed whether specific consulting firm characteristics impacted the turnaround response.

\section{Data Analysis}

Factor analysis was used to transform the 16 factor items of our dependent and independent variables into three variables: retrenchment activities, recovery activities, and turnaround performance. Confirmatory factor analysis (CFA) indicated good fit ('initial stage': $\chi^{2}(101)=102.2, \mathrm{p}<.001, \mathrm{CFI}=.99, \mathrm{SRMR}=.05, \mathrm{RMSEA}=.02 ;$ 'advanced stage': $\chi^{2}(101)=159.7$, $\mathrm{p}<.001, \mathrm{CFI}=.96, \mathrm{SRMR}=.07, \mathrm{RMSEA}=.04)$. To reduce the threat of same-source bias in the data (Podsakoff, MacKenzie, Lee, \& Podsakoff, 2003), a Harman single-factor test for each turnaround stage revealed three factors with eigenvalues greater than 1 , with the largest factor accounting for $37 \%$ per cent of the variance. A Kolmogorov-Smirnov goodness-of-fit test indicated no significant differences from a normal distribution $(\mathrm{p}<0.10)$. Finally, a one factor CFA model revealed a poor fit $\left(\chi^{2}(324)=1196.5, \mathrm{p}<.001, \mathrm{CFI}=.46, \mathrm{SRMR}=.16, \mathrm{RMSEA}=.16\right)$.

We then used hierarchical (step-wise) regression analysis to test our hypotheses. Similar to related duality studies (He \& Wong, 2004; Jansen, Simsek, \& Cao, 2012), we measured the 
interaction between retrenchment and recovery by means of the product of the two retrenchment and recovery scores. Because retrenchment and recovery were measured on different scales, we followed prior studies' advice to mean-center the variables prior to the creation of the interaction term (e.g., Aiken \& West, 1991). We then computed the relative bias in the retrenchmentrecovery balance within each stage. We used Uotila and colleagues' (2009) approach to assess the relative bias towards retrenchment compared to recovery by dividing the standardized individual retrenchment score by the sum of the standardized retrenchment and recovery scores. Hence, high scores indicate a retrenchment bias, whereas low scores represent a recovery bias.

To test Hypothesis 1 and 2 regarding a biased balance between retrenchment and recovery, we applied the median cut-off criterion to categorize different intra-stage turnaround behaviors. For both turnaround stages, firms were classified along two dimensions (see Figure 2): their interaction effects between the retrenchment and recovery ("weak" vs. "strong” interactions) and their relative bias towards retrenchment rather than recovery ("low" vs. "high" retrenchment/recovery ratio). This led to four distinct categories of turnaround behaviors within each turnaround stage: retrenchment dominance (weak interaction; high retrenchment/recovery ratio), balance with retrenchment bias (strong interaction; high retrenchment/recovery ratio), recovery dominance (weak interaction; low retrenchment/recovery ratio), and balance with recovery bias (strong interaction; low retrenchment/recovery ratio). We subsequently used the four categories as measures for the quantitative analysis in respect of Hypothesis 1 and 2.

Insert Figure 2 about here

To test Hypothesis 3 regarding a sequential balance between retrenchment and recovery, we classified turnaround firms along two dimensions: interrelations within stages and change between stages. First, we measured the interrelations within the stages by means of both 
turnaround stages' average interaction score. The measure indicates the extent to which turnaround firms engage in simultaneous retrenchment and recovery throughout the turnaround process. We classified firms into the "weak" or the "strong” interrelations categories, using the median cut-off. Second, we measured the change between the stages by means of the difference between a firm's relative focus on recovery in the advanced turnaround stage and its relative focus on recovery in the initial turnaround stage. We again used the median-cut off criterion to distinguish between "weak" and "strong” changes.

This led to four consistent inter-stage turnaround patterns (see Figure 3): First, the simultaneous attention (high interaction and low change) category comprises turnaround firms that engaged in both retrenchment and recovery (high interaction) and maintained this dual focus throughout the turnaround process (low change). Arogyaswamy et al. (1995) describe a similar turnaround behavior. Second, the sequential attention category consists of turnaround firms that shifted from one-sided retrenchment in the initial turnaround stage to one-sided recovery in the advanced stage (low interaction and high change). Robbins and Pearce (1992) and other proponents of the sequential perspective (e.g., Morrow et al., 2004) describe such turnaround behaviors. Third, the shifting balance category refers to turnaround firms that shifted from a retrenchment bias in the initial stage to a recovery bias in the advanced stage (high interaction and high change). Finally, the others category (low interaction and low change) includes turnaround firms that either maintained a one-sided attention to retrenchment or a one-sided attention to recovery throughout the entire turnaround process, or shifted from a recovery focus in the initial stage to a retrenchment focus in the advanced stage of the turnaround process.

Insert Figure 3 about here 


\section{Results}

Table 1 presents the descriptive statistics and correlations of the study's variables. Table 2 presents the regression results of turnaround performance in the initial and the advanced stages. While the baseline model (model 1) shows the control variables, model 2 introduces the retrenchment activities and model 3 adds the recovery activities. The interaction effects between retrenchment and recovery are added in model 4 . The relative focus between retrenchment and recovery is displayed in model 5. The variance inflation factor (VIF) values for all models remained below accepted cut-off levels (Neter, Wasserman, \& Kutner, 1985).

\section{Insert Tables 1 and 2 about here}

Model 4 depicts the assumed positive interaction effects of combined retrenchment and recovery activities on turnaround performance in the initial stage $(b=0.196, p<0.01$ ) and the advanced stage $(\mathrm{b}=0.177, \mathrm{p}<0.05)$. In model 5 , we report the results for the different intrastage categories. In the initial turnaround stage, the retrenchment dominance group served as the reference category. The coefficients of the three remaining turnaround behaviors should thus be interpreted in relation to this group. The control variable liquidity ( $b=0.745, p<0.05$ ), the balance with retrenchment bias $(\mathrm{b}=0.899, \mathrm{p}<0.05)$ and the retrenchment dominance $(\mathrm{b}=$ 2.551, $\mathrm{p}<0.05$ ) were positively and significantly related to turnaround performance during the initial stage. Conversely, the balance with recovery bias $(\mathrm{b}=-0.539, \mathrm{p}>0.10)$ and the recovery dominance $(\mathrm{b}=-0.238, \mathrm{p}>0.10$ ) categories were negative and insignificant. Since the balance with retrenchment bias showed a positive and significant relationship with turnaround performance, Hypothesis 1 is supported.

In respect of the advanced stage, the control variable firm size $(\mathrm{b}=0.275, \mathrm{p}<0.01)$, the balance with recovery bias $(\mathrm{b}=3.370, \mathrm{p}<0.001)$ and the recovery dominance categories $(\mathrm{b}=$ 
0.881, $\mathrm{p}<0.05$ ) showed a positive and significant interaction with turnaround performance, while the balance with retrenchment bias $(\mathrm{b}=0.702, \mathrm{p}>0.10)$ and the retrenchment dominance $(b=-0.005, p>0.10)$ categories were insignificant. Since the balance with recovery bias showed a positive and significant relationship with turnaround performance, Hypothesis 2 is supported.

Table 3 compares the performance effects of different inter-stage turnaround behaviors. In model 2, the simultaneous turnaround behavior served as the reference group. With regard to our control variables, firm size $(\mathrm{b}=0.310, \mathrm{p}<0.01)$ indicated a positive significant effect on our dependent variable. In comparison to all other groups, the shifting balance turnaround behavior $(\mathrm{b}=1.246, \mathrm{p}<0.01)$ indicated the only positive and significant $(\mathrm{p}>0.05)$ relationship with turnaround performance. Hypothesis 3 is therefore supported.

Insert Table 3 about here

We conducted additional regression analyses by adding several other control variables. Given that these analyses did not change our research findings, we present them only briefly. First, we included a dummy variable distinguishing service and manufacturing firms (O'Neill, 1981). Second, we controlled for asset and cost retrenchment as suggested by prior research (Lim et al., 2013; Morrow et al., 2004; Robbins \& Pearce, 1992). Finally, a country dummy accounted for national differences (Bruton et al., 2003). None of these variables had a significant effect on performance.

\section{Discussion}

This study explored the retrenchment-recovery duality in corporate turnarounds and presented novel ways of managing paradoxes in resource-scarce organizations. We now build upon these findings from a corporate turnaround context to develop a set of potentially 
generalizable theoretical contributions to the paradox literature. Collectively, these contributions shape the outlines of a process perspective for managing dualities that integrates the synergistic combination and temporal separation strategies.

\section{Theoretical Contributions}

The prior paradox literature has presented synergistic combination and temporal separation as opposed, alternative strategies to manage organizational paradoxes (e.g., Gupta et al., 2006; Poole \& Van de Ven, 1989; Raisch, Birkinshaw, Probst, \& Tushman, 2009). The general recommendation was to select one or the other approach, dependent on a number of contingencies. Conversely, we provide theoretical arguments and empirical evidence that a synthesis between these strategies is possible. A synthesis accentuates and combines the two approaches' positive elements while minimizing their negative effects (Farjoun, 2010). The synthesis is enabled through the combination of two novel mechanisms of paradox resolution biased balance and shifting balance.

The biased balance allows leaders in paradoxical situations, which create uncertainty and ambiguity that threaten them cognitively and emotionally (Lewis, 2000; Smith \& Berg, 1987), to follow their natural inclination to prioritize one of the opposing poles over the other (Smith, 2014; Vince \& Broussine, 1996). This should reduce the managerial resource requirements (Smith \& Tushman, 2005), and thus the risk of erroneous decision making due to cognitive overloads (Huber, 1991); but also the financial resource requirements to implement managerial initiatives (Gupta et al., 2006). Since minimum levels of both poles are maintained at all times, organizations also reduce the risk of splitting interwoven elements (Smith, 2014), blurring their interrelatedness (Smith \& Lewis, 2011), and losing their mutually enabling qualities (Farjoun, 
2011). The biased balance thus allows for combining elements from both opposites in a way that allows for benefitting from their mutually enabling effects while effectively protecting the organization from their mutually harmful consequences. ${ }^{1}$

Further, the shifting balance allows leaders to partly nest the paradoxical tensions in time, which allows more room for enabling complementarities (Farjoun, 2010). Organizations gain the time that is required to generate additional resources by means of temporal separation, which make subsequent paradox resolution more likely (Voss \& Voss, 2014). Contrary to pure forms of temporal separation, which suggest discrete moves from one opposing element to another (Gersick, 1991; Tushman \& Romanelli, 1985), the shifting balance approach preserves the simultaneous quality of these elements at all times. The more dualities' countervailing symbiotic influences become available, the more they can, in the long run, draw retrenchment and recovery together, enabling virtuous and mutually enabling cycles that foster turnaround performance.

Taken together, the concepts of biased balance and shifting balance enable a synthesis of multiple approaches to paradox management. In their landmark study, Poole and Van de Ven (1989) presented synergistic combination and temporal separation as distinct and alternative methods for handling paradoxes, but admitted that they may be combined in practice. Our analysis provides theoretical arguments and empirical evidence that such a combinative approach may sometimes be required to address paradoxes successfully, in particular in resource-scarce organizations. Further research will be required to ascertain the usefulness of such combinative approaches, and more specifically the two mechanisms that enable them, in different contexts.

Finally, our novel perspective to paradox management is one of the first that takes a process or stage perspective. Researchers have frequently criticized prior paradox studies for their static,

\footnotetext{
${ }^{1}$ The concept of biased balance has been used in other disciplines (i.e. philosophy, natural sciences). Generally, a biased balance is defined as a two-arm balance whose fulcrum is not necessarily located at the middle of the two pans (Le Menestrel, van den Hove, \& Bettignies, 2002).
} 
cross-sectional perspectives (e.g., Raisch et al., 2009; Smith \& Lewis, 2011), which may oversimplify the complex and dynamic nature of paradox (Schad et al., forthcoming). While there are a few notable exceptions, such as Jazarbkowski et al.'s (2013) study of reinforcing cycles in paradox management, this is to our best knowledge the first stage perspective distinguishing different phases and highlighting transitions in managing organizational dualities. The particular value of such stage models is that they allow for identifying more complex paradox resolution mechanisms, such as the combination of the dual balancing mechanisms to address dualities in our study. We encourage further process-oriented and longitudinal perspectives in future paradox research.

\section{Implications for Managerial Practice}

The emergence of paradoxical thinking in management theory (e.g., Luscher \& Lewis, 2008; Sundaramurthy \& Lewis, 2003) has also helped practitioners around the world to reach a better understanding of today’s complex strategic challenges. In this vein, our study provides managers with strategic orientation on how to behave in resource scarcity situations that demand both measures to stabilize operations and change strategic direction.

First, we indicate that turnarounds require a balanced managerial focus on retrenchment and recovery. Consistent with early case study evidence (e.g., Barker \& Mone, 1998; Cameron, Kim, \& Whetten, 1987; Sutton, Eisenhardt, \& Jucker, 1986), we believe that top management's tendency to overly focus on efficiency and centralization can severely affect the firm's chances of recovery. Managers need to simultaneously and immediately engage in strategic change activities that counterbalance their retrenchment activities. Consequently, managers should start by defining and communicating the turnaround's long-term objectives, which should increase the 
chances of a sustained performance improvement (e.g., Cameron, Freeman, \& Mishra, 1991; Martin \& Kimberly, 2008; Pajunen, 2006).

Second, according to the shifting balance perspective, managers not only have to manage the complexity that arises from balancing retrenchment and recovery in each phase, but also the dynamics that underlie the shift in balance over time. Turnarounds thus require a great deal of foresight and planning throughout the process (e.g., Arogyaswamy et al., 1995; Morrow et al., 2004). Managers need to apply a coherent response (e.g., Arogyaswamy et al., 1995) and ensure that organizational resources are allocated to the right activities at the right time.

From a managerial point of view, this is difficult because it implies knowing when and how to initiate a shift in focus from one activity to another. Managers need to avoid falling into 'inertia traps’ (Ahuja \& Lampert, 2001), which can arise if they maintain their initial focus on retrenchment for too long. Conversely, if they move on too early in the process or shift too strongly, there is a great risk that the firm will run out of resources before it has implemented its recovery activities. This inherent complexity may be an important reason for turnaround initiatives’ high failure rates.

Finally, prior research has shown that managers subjected to the uncertainty and stress of turnaround situations have a tendency to push firm towards massive change (Filatotchev \& Toms, 2003), while suffering from a reduced attention span and ability to process information (Staw et al., 1981). If this is indeed true, the chances of the successful implementation of a balanced turnaround approach may critically depend on the effectiveness of the turnaround firm’s leadership capabilities, governance structures, and its risk management approach, which can help ensure that a balanced approach towards turnaround management is maintained. 


\section{Limitations and Future Research}

Similar to other studies that aim to capture organizational processes' complexity, our study has several limitations. First, this study explores the overall dynamics of generic turnaround strategies without specifying interactions between asset and cost retrenchment (e.g., Lim et al., 2013) or between internally and externally directed recovery activities (e.g., Barker \& Duhaime, 1997). Future research might explore these interrelationships to further refine our findings.

Second, our study follows suggestions from extant strategy process literature (e.g., Van De Ven, 1992) and uses predefined stages to analyze turnaround behavior. While this approach allows us to uncover certain dynamics throughout both turnaround stages, we cannot provide detailed insights into the dynamics within each stage. We encourage research to investigate each stage’s dynamics, possibly through longitudinal case studies.

Third, the study's methodological approach calls for caution in interpreting our findings: while we cannot provide further insights into the specific organizational attributes facilitating the implementation process (e.g., structure, culture, governance), we consider future studies analyzing turnaround firms' implementation of biased balance and shifting balance approaches as a promising research avenue. In particular, exploring leadership characteristics enabling these dualities (Smith \& Tushman, 2005) has the potential to uncover success strategies in managing and dealing with paradoxical tensions.

Fourth, applying the median cut-off criteria when grouping distinct strategic behavior during corporate turnarounds aims at generalizing our results. However, such categorization fails to acknowledge several differences within pre-defined groups (i.e., a strong dominant retrenchment strategy vs. a weak dominant retrenchment strategy) and thus we call for future empirical studies analyzing a more fine-grained categorization of our turnaround strategies. 
Fifth, several studies have emphasized the contextual impact on turnaround behavior and performance (Ndofor et al., 2013; Trahms et al., 2013). We therefore consider it as important to assess the strength of the relative bias between retrenchment and recovery for varying cases of severity and cause of decline in future research.

Finally, we do not know whether our findings from the Central European region can be applied to other geographical regions. Prior studies have shown that industry conditions, regulatory contexts, and cultural environments can shape turnaround activities and influence their performance implications (e.g., Bruton et al., 2003). We thus welcome comparative studies that test elements of our theory across different institutional and cultural environments.

\section{Conclusion}

The paradox literature has provided synergistic combination and temporal separation as possible strategies to address paradoxical demands within organizations. This study's empirical results integrate and enrich extant solutions by providing large-scale empirical evidence of biased balance and shifting balance approaches to address dualities in resource-scarce organizations. Instead of either/or choices, we further clarify the both/and approaches that embrace dualities rather than choosing one side of the opposition over the other. We argue how these particularly complex and difficult approaches can be enabled through skillful use and combination of multiple paradox management tactics within and across different periods of time. It is our hope that the ideas presented in this paper motivate future research on strategic paradoxes in today’s increasingly complex environments. 


\section{REFERENCES}

Ahuja, G. \& Lampert, C. 2001. Entrepreneurship in the large corporation: A longitudinal study of how established firms create breakthrough inventions. Strategic Management Journal, 22: 521-543.

Aiken, L.S. \& West, S.G. 1991. Multiple Regression: Testing and Interpreting Interactions. Thousand Oaks, CA: Sage.

Andriopoulos, C. \& Lewis, M.W. 2009. Exploitation-exploration tensions and organizational ambidexterity: Managing paradoxes of innovation. Organization Science 20: 696-717.

Arogyaswamy, K., Barker, V.L., \& Yasai-Ardekani, M. 1995. Firm turnarounds: An integrative two-stage model. Journal of Management Studies 32: 493-525.

Barker, V.L. \& Duhaime, I.M. 1997. Strategic change in the turnaround process: Theory and empirical evidence. Strategic Management Journal 18: 13-38.

Barker, V.L. \& Mone, M.A. 1994. Retrenchment: Cause of turnaround or consequence of decline? Strategic Management Journal 15: 395-405.

Barker, V.L. \& Mone, M.A. 1998. The mechanistic structure shift and strategic reorientation in declining firms attempting turnarounds. Human Relations 51: 1227-1258.

Bergh, D. \& Gibbons, P. 2011. The stock market reaction to the hiring of management consultants: a signalling theory approach. Journal of Management Studies 48: 544-567.

Besharov, M. \& Smith, W. 2014. Multiple institutional logics in organizations: Explaining their varied nature and implications. Academy of Management Review forthcoming: doi: 10.5465/amr.2011.0431

Bibeault, D.B. 1982. Corporate Turnaround: How Managers Turn Losers into Winners, New York: McGraw-Hill.

Boumgarden, P., Nickerson, J., \& Zenger, T.R. 2012. Sailing into the wind: Exploring the relationships among ambidexterity, vacillation, and organizational performance. Strategic Management Journal, 33: 587-610.

Bower, J.L. \& Gilbert, C. 2005. From Resource Allocation Strategy, Oxford: Oxford University Press.

Boyne, G. \& Meier, K. 2009. Environmental change, human resources and organizational turnaround. Journal of Management Studies 46: 835-863.

Bruton, G.D., Ahlstrom, D. \& Wan, J. 2003. Turnaround in East Asian firms: Evidence from ethnic overseas Chinese communities. Strategic Management Journal 24: 519-540.

Burgelman, R.A. 2002. Strategy as vector and the inertia of coevolutionary lock-in. Administrative Science Quarterly 47: 325-357.

Burns, T. \& Stalker, G.M. 1961. The Management of Innovation, London: Tavistock Publications.

Cameron, K. 1986. Effectiveness as paradox: Consensus and conflict in conceptions of organizational effectiveness. Management Science 32: 539-553.

Cameron, K.S., Freeman, S.J., \& Mishra, A.K. 1991. Best practices in white-collar downsizing: Managing contradictions. Academy of Management Executive 5: 57-73.

Cameron, K.S., Kim, M.U., \& Whetten, D.A. 1987. Organizational effects of decline and turbulence. Administrative Science Quarterly 32: 222-240. 
Cameron, K.S. \& Quinn, R.E. 1988. Organizational paradox and transformation. In: Cameron, K.S. and Quinn, R.E. (eds) Paradox and Transformation: Toward a Theory of Change in Organization and Management. Cambridge, MA: Ballinger.

Cardinal, L.B., Sitkin, S.B., \& Long, C.P. 2004. Balancing and rebalancing in the creation and evolution of organizational control. Organization Science 15: 411-431.

Castrogiovanni, G.J. \& Bruton, G.D. 2000. Business turnaround processes following acquisitions: Reconsidering the role of retrenchment. Journal of Business Research 48: 25-34.

Chae, B. \& Bloodgood, J.M. 2006. The paradoxes of knowledge management: An Eastern philosophical perspective. Information and Organization 16: 1-26.

Chen, G. \& Hambrick, D.C. 2012. CEO replacement in turnaround situations: Executive (mis)fit and its performance implications. Organization Science 23: 225-243.

Chowdhury, S.D. 2002. Turnarounds: A stage theory perspective. Canadian Journal of Administrative Sciences 19: 249-266.

Clegg, S.R., Vieira da Cunha, J. \& Pina e Cunha, M. 2002. Management paradoxes: A relational view. Human Relations 55: 483-503.

Datta, D.K. 1991. Organizational fit and acquisition performance: Effects of post-acquisition integration. Strategic Management Journal 12: 281-297.

Davydenko, S. \& Franks, J. 2008. Do bankruptcy codes matter? A study of defaults in France, Germany and the UK. Journal of Finance, 63: 565-608.

Dess, G.G. \& Robinson, R.B. 1984. Measuring organizational performance in the absence of objective measures: The case of the privately-held firm and conglomerate business unit. Strategic Management Journal 5: 265-273.

Eisenhardt, K.M. 2000. Paradox, spirals, ambivalence: The new language of change and pluralism. Academy of Management Review 25: 703-705.

Evans, P. 1999. HRM on the edge: A duality perspective. Organization 6: 325-338.

Farjoun, M. 2010. Beyond dualism: Stability and change as a duality. Academy of Management Review 35: 202-225.

Filatotchev, I. \& Toms, S. 2003. Corporate governance, strategy and survival in a declining industry: A study of UK cotton textile companies. Journal of Management Studies 40: 895-920.

Filatotchev, I. \& Toms, S. 2006. Corporate governance and financial constraints on strategic turnarounds. Journal of Management Studies 43: 407-433.

Gersick, C.J.G. 1991. Revolutionary change theories: A multilevel exploration of the punctuated equilibrium paradigm. Academy of Management Review 16: 10-36.

Gilbert, C. 2005. Unbundling the structure of inertia: Resource versus routine rigidity. Academy of Management Journal 48: 741-763.

Grinyer, P.H., Mayes, D., \& McKiernan, P. 1988. Sharpbenders: The Secrets of Unleashing Corporate Potential., Oxford: Basil Blackwell.

Gupta, A.K., Smith, K.G., \& Shalley, C.E. 2006. The interplay between exploration and exploitation. Academy of Management Journal 4: 693-706.

He, Z.L. \& Wong, P.K. 2004. Exploration vs. exploitation: An empirical test of the ambidexterity hypothesis. Organization Science 15: 481-494. 
Henderson, R.M. \& Clark, K.B. 1990. Architectural innovation: The reconfiguration of existing product technologies and the failure of established firms. Administrative Science Quarterly 35: 9-30.

Hitt, M.A., Hoskisson, R.E., Johnson, R.A., \& Moesel, D. 1996. The market for corporate control and firm innovation. Academy of Management Journal 39: 1084-1119.

Hofer, C.W. 1980. Turnaround strategies. Journal of Business Strategy 1: 19-31.

Hoffman, R.C. 1989. Strategies for corporate turnarounds: What do we know about them? Journal of General Management 14: 46-66.

Huber, G. 1991. Organizational learning: The contributing processes and literatures. Organization Science, 2: 88-115.

Huber, G. \& Power, D. 1985. Retrospective reports of strategic-level managers: Guidelines for increasing their accuracy. Strategic Management Journal 6: 171-180.

Jansen, J.J.P., Simsek, Z., \& Cao, Q. 2012. Ambidexterity and performance in multiunit contexts: Cross-level moderating effects of structural and resource attributes. Strategic Management Journal 33: 1286-1303.

Jarzabkowski, P., Lê, J., \& Van de Ven, A.H. 2013. Responding to competing strategic demands: How organizing, belonging, and performing paradoxes coevolve. Strategic Organization 11: $245-280$.

Khandwalla, P. 1983. Turnaround management of mismanaged complex organizations. International Studies of Management \& Organization 13: 5-41.

Klarner, P. \& Raisch, S. 2013. Move to the beat - Rhythms of change and firm performance. Academy of Management Journal 56: 160-184.

Kraatz, M. \& Block, E. 2008. Organizational implications of institutional pluralism. In: Greenwood, R., Oliver, C., \& Suddaby, R. (eds) Handbook of Organizational Institutionalism. London: Sage Publication, 243-275.

Lamberg, J.-A. \& Pajunen, K. 2005. Beyond the metaphor: The morphology of organizational decline and turnaround. Human Relations 58: 947-980.

Le Menestrel, M., van den Hove, S., \& Bettignies, H.-C. 2002. Processes and consequences in business ethical dilemmas: The oil industry and climate change. Journal of Business Ethics 41: 251-266.

Leana, C.R. \& Barry, B. 2000. Stability and change as simultaneous experiences in organizational life. Academy of Management Review 25: 753-759.

Leonard-Barton, D. 1992. Core capabilities and core rigidities: A paradox in managing new product development. Strategic Management Journal 13: 111-125.

Lewis, M.W. 2000. Exploring paradox: Toward a more comprehensive guide. Academy of Management Review 25: 760-777.

Lewis, M.W. \& Smith, W. (forthcoming) Paradox as a meta-theoretical perspective: Sharpening the focus and widening the scope. Journal of Applied Behavioral Science.

Lim, D.S.K., Celly, N., Morse, E.A., \& Rowe, W.G. 2013. Rethinking the effectiveness of asset and cost retrenchment: The contingency effects of a firm's rent creation mechanism. Strategic Management Journal 34: 42-61.

Lohrke, F.T., Ahlstrom, D., \& Bruton, G. 2012. Extending turnaround process research: Important lessons from the US civil war. Journal of Management Inquiry 21: 217-234. 
Luscher, L. \& Lewis, M.W. 2008. Organizational change and managerial sensemaking: Working through paradox. Academy of Management Journal 51: 221-240.

March, J.G. 1991. Exploration and exploitation in organizational learning. Organization Science 2: 71-87.

Martin, R.D. \& Kimberly, J.R. 2008. Back from the brink: Managerial lessons from the turnaround at the University of Pennsylvania health system. Organizational Dynamics 37: 97-111.

McClelland, P.L., Liang, X., \& Barker, V.L. 2010. CEO commitment to the status-quo: Replication and extension using content analysis. Journal of Management 36: 1251-1277.

Michael, S.C. \& Robbins, D.K. 1998. Retrenchment among small manufacturing firms during recession. Journal of Small Business Management 36: 35-45.

Mone, M.A., McKinley, W. \& Barker, V.L. 1998. Organizational decline and innovation: A contingency framework. Academy of Management Review 23: 115-132.

Morrow, J.L., Johnson, R.A. \& Busenitz, L.W. 2004. The effects of cost and asset retrenchment on firm performance: The overlooked role of a firm's competitive environment. Journal of Management 30: 189-208.

Morrow, J.L., Sirmon, D.G., Hitt, M.A., \& Holcomb, T.R. 2007. Creating value in the face of declining performance: Firm strategies and organizational recovery. Strategic Management Journal 28: 271-283.

Musteen, M., Liang, X., \& Barker, V.L. 2011. Personality, perceptions and retrenchment decisions of managers in response to decline: Evidence from a decision-making study. The Leadership Quarterly 22: 926-941.

Naveh, E. \& Erez, M. 2004. The duality of innovation and attention to detail in quality improvement initiatives. Management Science 50: 1576-1586.

Ndofor, H.A., Vanevenhoven, J., \& Barker, V.L. 2013. Software firm turnarounds in the 1990s: An analysis of reversing decline in a growing, dynamic industry. Strategic Management Journal 34: 1123-1133.

Neter, J., Wasserman, W., \& Kutner, M. (1985) Applied Linear Statistical Model, Homewood, IL: Irwin.

O'Neill, H.M. 1981. Turnaround Strategies in the Commercial Banking Industry. Ann Arbor, MI: UMI Research Press.

O'Neill, H.M. 1986. An analysis of the turnaround strategy in commercial banking. Journal of Management Studies 23: 165-188.

O’Reilly, C.A. \& Tushman, M.L. 2008. Ambidexterity as a dynamic capability: Resolving the innovator's dilemma. Research in Organizational Behavior 28: 185-206.

Pajunen, K. 2005. Comparative causal analysis in processual strategy research: A study of causal mechanisms in organizational decline and turnarounds. Advances in Strategic Management 22: 415-456.

Pajunen, K. 2006. Stakeholder influences in organizational survival. Journal of Management Studies 43: 1261-1288.

Pearce, J.A. \& Robbins, D.K. 2008. Strategic transformation as the essential last step in the process of business turnaround. Business Horizons 51: 121-130. 
Pearce, J.A. \& Robbins, K.D. 1993. Toward improved theory and research on business turnaround. Journal of Management 19: 613-636.

Pearce, J.A. \& Robbins, K.D. 1994. Retrenchment remains the foundation of business turnaround. Strategic Management Journal 15: 407-417.

Podsakoff, P., MacKenzie, S., Lee, J., \& Podsakoff, N.P. 2003. Common method biases in behavioral research: A critical review of the literature and recommended remedies. Journal of Applied Psychology 88: 879-903.

Poole, M.S. \& Van de Ven, A.H. 1989. Using paradox to build management and organization theories. Academy of Management Review 14: 562-578.

Powell, T.C. 1992. Organizational alignment as a competitive advantage. Strategic Management Journal 13: 119-134.

Raisch, S. 2008. Balanced structures: Designing organizations for profitable growth. Long Range Planning 41: 483-508.

Raisch, S. \& Birkinshaw, J. 2008. Organizational ambidexterity: Antecedents, outcomes, and moderators. Journal of Management 34: 375-409.

Raisch, S., Birkinshaw, J., Probst, G., \& Tushman, M. 2009. Organizational ambidexterity: Balancing exploitation and exploration for sustained performance. Organization Science 20: 685-695.

Robbins, D.K. \& Pearce, J.A. 1992. Turnaround: Retrenchment and recovery. Strategic Management Journal 13: 287-309.

Schad, J., Lewis, M., Raisch, S., \& Smith, W. 2016. Paradox research in management science: The first 25 years and the next 25 years. Academy of Management Annals forthcoming.

Schmitt, A., Borzillo, S., \& Probst, G. 2012. Don't let knowledge walk away: Knowledge retention during employee downsizing. Management Learning 43: 53-74.

Schmitt, A. \& Raisch, S. 2013. Corporate turnarounds: The duality of retrenchment and recovery. Journal of Management Studies 50: 1216-1244.

Seo, M.G., Putnam, L.L., \& Bartunek, J.M. 2004. Dualities and tensions of planned organizational change. In: Poole M.S. \& Van De Ven, A.H. (eds) Handbook of Organizational Change and Innovation. Oxford: Oxford University Press, 73-107.

Sheppard, J.P. \& Chowdhury, S.D. 2005. Riding the wrong wave: Organizational failure as a failed turnaround. Long Range Planning 38: 239-260.

Siggelkow, N. \& Levinthal, D.A. 2003. Temporarily divide to conquer: Centralized, decentralized, and reintegrated organizational approaches to exploration and adaptation. Organization Science 14: 650-669.

Simsek, Z., Heavey, C., \& Veiga J.F. 2009. A typology for aligning organizational ambidexterity's conceptualizations, antecedents, and outcomes. Journal of Management Studies 46: 864-894.

Smith, K. \& Berg, D. 1987. Paradoxes of Group Life., San Francisco: Josey-Bass.

Smith, W. 2014. Dynamic decision making: A model of senior leaders managing strategic paradoxes. Academy of Management Journal forthcoming: doi: 10.5465/amj.2011.0932.

Smith, W., Binns, A., \& Tushman, M.L. 2010. Complex business models: Managing strategic paradoxes simultaneously. Long Range Planning 43: 448-461. 
Smith, W. \& Lewis, M.W. 2011. Toward a theory of paradox: A dynamic equilibrium model of organizing. Academy of Management Review 36: 381-403.

Smith, W. \& Tushman, M.L. 2005. Managing strategic contradictions: A top management model for managing innovation streams. Organization Science 16: 522-536.

Staw, B.M., Sandelands, L.E., \& Dutton, J.E. 1981. Threat-rigidity effects in organizational behavior: A multilevel analysis. Administrative Science Quarterly 26: 501-524.

Sundaramurthy, C. \& Lewis, M.W. 2003. Control and collaboration: Paradoxes of governance. Academy of Management Review 28: 397-415.

Sutton, R.I., Eisenhardt, K.M., \& Jucker, J.V. 1986. Managing organizational decline: Lessons from Atari. Organizational Dynamics 14: 17-29.

Trahms, C.A., Ndofor, H.A., \& Sirmon, D.G. 2013. Organizational decline and turnaround: A review and agenda for future research. Journal of Management 39: 1277-1307.

Tushman, M.L., \& Romanelli, E. 1985. Organizational evolution: A metamorphosis model of convergence and reorientation. Research in Organizational Behavior 7: 171-222.

Uotila, J., Maula, M., Keil, T., \& Zahra, S.A. 2009. Exploration, exploitation, and financial performance: Analysis of S\&P 500 corporations. Strategic Management Journal 30: 221231.

Van De Ven, A.H. 1992. Suggestions for studying strategy process: A research note. Strategic Management Journal 13: 169-188.

Van de Ven, A.H. \& Poole, M.S. 1988. Paradoxical requirements for a theory of organizational change. In: Quinn, R.E. \& Cameron, K.S. (eds) Paradox and Transformation: Toward a Theory of Change in Organization and Management. Cambridge, MA: Ballinger, 19-61.

Vince, R. \& Broussine, M. 1996. Paradox, defense and attachment: Accessing and working with emotions and relations underlying organizational change. Organization Studies 17: 1-21.

Voss, G.B. \& Voss, Z.G. 2013. Strategic ambidexterity in small and medium-sized enterprises: Implementing exploration and exploitation in product and market domains. Organization Science 24: 1459-1477.

Walrave, B., van Oorschot, K.E., \& Romme, A.G.L. 2011. Getting trapped in the surpression of exploration: A simulation model. Journal of Management Studies 48: 1727-1751.

Zollo, M. \& Meier, D. 2008. What is M\&A performance? Academy of Management Perspectives 22: 55-77. 
TABLE 1

Means, standard deviations, and correlations ${ }^{a}$

\begin{tabular}{|c|c|c|c|c|c|c|c|c|c|c|c|c|}
\hline & & Mean & St.d. & (1) & (2) & (3) & (4) & (5) & (6) & (7) & (8) & (9) \\
\hline \multicolumn{13}{|c|}{ Initial stage } \\
\hline (1) & Retrenchment & 4.51 & 1.25 & (.86) & & & & & & & & \\
\hline (2) & Recovery & 3.05 & 1.15 & .05 & $(.85)$ & & & & & & & \\
\hline (3) & Turnaround performance & 4.91 & 1.59 & $.45^{* * *}$ & $.33^{* * *}$ & (.94) & & & & & & \\
\hline (4) & Liquidity ratio & 0.96 & 0.66 & .07 & -.01 & $.23^{*}$ & / & & & & & \\
\hline (5) & Leverage ratio & 59.10 & 36.01 & -.05 & -.02 & -.08 & $-.74^{* * *}$ & / & & & & \\
\hline (6) & Cause of decline & 1.19 & 0.67 & -.09 & -.07 & -.12 & -.03 & -.04 & / & & & \\
\hline (7) & Firm size ${ }^{b}$ & 6.08 & 1.53 & .11 & -.12 & $.24^{*}$ & -.11 & .08 & .10 & / & & \\
\hline (8) & Industry environment & 0.96 & 0.51 & -.01 & $.26 * *$ & .01 & -.07 & .07 & -.02 & .06 & / & \\
\hline (9) & Consulting firm & 18.15 & 8.46 & -.05 & .05 & .09 & -.03 & .03 & $-.22 *$ & $.24^{*}$ & .13 & / \\
\hline \multicolumn{13}{|c|}{ Advanced stage } \\
\hline (1) & Retrenchment & 3.57 & 1.17 & $(.86)$ & & & & & & & & \\
\hline (2) & Recovery & 4.03 & 1.32 & .06 & $(.86)$ & & & & & & & \\
\hline (3) & Turnaround performance & 4.91 & 1.59 & $.35^{* * *}$ & $.46^{* * *}$ & (.94) & & & & & & \\
\hline (4) & Liquidity ratio & 1.01 & 0.77 & .08 & .12 & .15 & / & & & & & \\
\hline (5) & Leverage ratio & 47.47 & 29.74 & -.05 & -.13 & $-.18^{*}$ & $-.60 * * *$ & / & & & & \\
\hline (6) & Cause of decline & 1.19 & 0.67 & .01 & -.08 & -.12 & -.05 & .05 & / & & & \\
\hline (7) & Firm size $e^{b}$ & 5.86 & 1.57 & .17 & -.10 & $.21^{*}$ & -.15 & .07 & .11 & / & & \\
\hline (8) & Industry environment & 0.96 & 0.51 & -.10 & -.05 & .01 & -.04 & -.02 & -.02 & .08 & / & \\
\hline (9) & Consulting firm & 18.15 & 8.46 & .05 & -.12 & .09 & .11 & $-.22 *$ & $-.23 *$ & $.22^{*}$ & .13 & / \\
\hline
\end{tabular}


TABLE 2

Intra-stage turnaround behavior and turnaround performance ${ }^{\text {a }}$

\begin{tabular}{|c|c|c|c|c|c|c|c|c|c|c|}
\hline \multirow[t]{2}{*}{ Turnaround performance } & \multicolumn{5}{|c|}{ Initital stage } & \multicolumn{5}{|c|}{ Advanced stage } \\
\hline & Model 1 & Model 2 & Model 3 & Model 4 & Model 5 & Model 1 & Model 2 & Model 3 & Model 4 & Model 5 \\
\hline \multicolumn{11}{|l|}{ Control variables } \\
\hline Liquidity & $\begin{array}{c}0.939^{* *} \\
(0.033)\end{array}$ & $\begin{array}{l}0.870^{* *} \\
(0.304)\end{array}$ & $\begin{array}{c}0.918^{* * *} \\
(0.278)\end{array}$ & $\begin{array}{c}0.976^{* * *} \\
(0.271)\end{array}$ & $\begin{array}{l}0.745^{*} \\
(0.330)\end{array}$ & $\begin{array}{c}0.197 \\
(0.244)\end{array}$ & $\begin{array}{c}0.117 \\
(0.234)\end{array}$ & $\begin{array}{c}0.061 \\
(0.206)\end{array}$ & $\begin{array}{c}0.066 \\
(0.202)\end{array}$ & $\begin{array}{c}0.307 \\
(0.245)\end{array}$ \\
\hline Leverage ratio & $\begin{array}{c}0.008 \\
(0.006)\end{array}$ & $\begin{array}{c}0.008 \\
(0.006)\end{array}$ & $\begin{array}{l}0.009^{+} \\
(0.005)\end{array}$ & $\begin{array}{l}0.009^{+} \\
(0.005)\end{array}$ & $\begin{array}{l}-0.007 \\
(0.001)\end{array}$ & $\begin{array}{l}-0.008 \\
(0.006)\end{array}$ & $\begin{array}{l}-0.008 \\
(0.006)\end{array}$ & $\begin{array}{l}-0.006 \\
(0.005)\end{array}$ & $\begin{array}{l}-0.005 \\
(0.005)\end{array}$ & $\begin{array}{l}-0.006 \\
(0.006)\end{array}$ \\
\hline Cause of decline & $\begin{array}{l}-0.305 \\
(0.228)\end{array}$ & $\begin{array}{l}-0.177 \\
(0.209)\end{array}$ & $\begin{array}{l}-0.147 \\
(0.190)\end{array}$ & $\begin{array}{c}-0.194 \\
(0.187)\end{array}$ & $\begin{array}{l}-0.224 \\
(0.219)\end{array}$ & $\begin{array}{l}-0.352 \\
(0.232)\end{array}$ & $\begin{array}{l}-0.345 \\
(0.221)\end{array}$ & $\begin{array}{l}-0.240 \\
(0.195)\end{array}$ & $\begin{array}{l}-0.258 \\
(0.192)\end{array}$ & $\begin{array}{l}-0.388^{+} \\
(0.229)\end{array}$ \\
\hline Firm size & $\begin{array}{c}0.290 * * \\
(0.100)\end{array}$ & $\begin{array}{l}0.222^{*} \\
(0.092)\end{array}$ & $\begin{array}{c}0.280 * * * \\
(0.085)\end{array}$ & $\begin{array}{c}0.287^{* * *} \\
(0.083)\end{array}$ & $\begin{array}{l}0.183^{+} \\
(0.099)\end{array}$ & $\begin{array}{c}0.268^{* *} \\
(0.101)\end{array}$ & $\begin{array}{l}0.208^{*} \\
(0.097)\end{array}$ & $\begin{array}{c}0.227^{* *} \\
(0.086)\end{array}$ & $\begin{array}{l}0.219 * \\
(0.084)\end{array}$ & $\begin{array}{c}0.275 * * \\
(0.099)\end{array}$ \\
\hline Industry environment & $\begin{array}{c}0.024 \\
(0.288)\end{array}$ & $\begin{array}{c}0.024 \\
(0.262)\end{array}$ & $\begin{array}{l}-0.281 \\
(0.248)\end{array}$ & $\begin{array}{c}-0.191 \\
(0.244)\end{array}$ & $\begin{array}{c}0.122 \\
(0.275)\end{array}$ & $\begin{array}{l}-0.023 \\
(0.295)\end{array}$ & $\begin{array}{c}0.095 \\
(0.283)\end{array}$ & $\begin{array}{c}0.124 \\
(0.249)\end{array}$ & $\begin{array}{c}0.165 \\
(0.245)\end{array}$ & $\begin{array}{l}-0.094 \\
(0.303)\end{array}$ \\
\hline Consulting firm & $\begin{array}{c}0.001 \\
(0.019)\end{array}$ & $\begin{array}{c}0.010 \\
(0.017)\end{array}$ & $\begin{array}{c}0.007 \\
(0.016)\end{array}$ & $\begin{array}{c}0.003 \\
(0.015)\end{array}$ & $\begin{array}{c}0.012 \\
(0.018)\end{array}$ & $\begin{array}{l}-0.006 \\
(0.019)\end{array}$ & $\begin{array}{l}-0.007 \\
(0.018)\end{array}$ & $\begin{array}{c}0.006 \\
(0.016)\end{array}$ & $\begin{array}{c}0.006 \\
(0.016)\end{array}$ & $\begin{array}{c}0.004 \\
(0.019)\end{array}$ \\
\hline Main effects & & & & & & & & & & \\
\hline Retrenchment & & $\begin{array}{c}0.507^{* * *} \\
(0.108)\end{array}$ & $\begin{array}{c}0.473^{* * *} \\
(0.099)\end{array}$ & $\begin{array}{c}0.490^{* * *} \\
(0.097)\end{array}$ & & & $\begin{array}{c}0.424^{* * *} \\
(0.113)\end{array}$ & $\begin{array}{c}0.388^{* * *} \\
(0.111)\end{array}$ & $\begin{array}{c}0.429 * * * \\
(0.110)\end{array}$ & \\
\hline Recovery & & & $\begin{array}{c}0.505^{* * *} \\
(0.110)\end{array}$ & $\begin{array}{c}0.579 * * * \\
(0.112)\end{array}$ & & & & $\begin{array}{c}0.531 * * * \\
(0.098)\end{array}$ & $\begin{array}{c}0.589 * * * \\
(0.099)\end{array}$ & \\
\hline Interaction effects & & & & & & & & & & \\
\hline Retrenchment x Recovery & & & & $\begin{array}{c}0.196 * * \\
(0.068)\end{array}$ & & & & & $\begin{array}{l}0.177^{*} \\
(0.080)\end{array}$ & \\
\hline Group effects ${ }^{b}$ & & & & & & & & & & \\
\hline Retrenchment dominance & & & & & $\begin{array}{l}2.551^{*} \\
(1.047)\end{array}$ & & & & & $\begin{array}{l}-0.005 \\
(0.433)\end{array}$ \\
\hline Balance with retrenchment bias & & & & & $\begin{array}{l}0.899^{*} \\
(0.401)\end{array}$ & & & & & $\begin{array}{c}0.702 \\
(0.463)\end{array}$ \\
\hline Balance with recovery bias & & & & & $\begin{array}{l}-0.539 \\
(0.441)\end{array}$ & & & & & $\begin{array}{c}3.370^{* * *} \\
(0.934)\end{array}$ \\
\hline Recovery dominance & & & & & $\begin{array}{l}-0.238 \\
(0.412)\end{array}$ & & & & & $\begin{array}{l}0.881^{*} \\
(0.441)\end{array}$ \\
\hline$R^{2}$ & 0.157 & 0.310 & 0.432 & 0.466 & 0.265 & 0.114 & 0.201 & 0.390 & 0.420 & 0.175 \\
\hline Adjusted $\mathrm{R}^{2}$ & 0.107 & 0.262 & 0.385 & 0.417 & 0.197 & 0.061 & 0.150 & 0.341 & 0.367 & 0.098 \\
\hline$\Delta R^{2}$ & & $0.153^{* * *}$ & $0.121^{* * *}$ & $0.035^{*}$ & & & $0.092^{* * *}$ & $0.184^{* * *}$ & $0.029 *$ & \\
\hline
\end{tabular}


TABLE 3

Inter-stage turnaround behavior and turnaround performance ${ }^{\text {a }}$

\begin{tabular}{|c|c|c|}
\hline \multirow[t]{2}{*}{ Turnaround performance } & \multicolumn{2}{|c|}{ Interstage turnaround behavior } \\
\hline & Model 1 & Model 2 \\
\hline \multicolumn{3}{|l|}{ Control variables } \\
\hline Liquidity ${ }^{b}$ & $\begin{array}{l}0.651^{+} \\
(0.034)\end{array}$ & $\begin{array}{l}0.541^{+} \\
(0.033)\end{array}$ \\
\hline Leverage ratio $^{\mathrm{b}}$ & $\begin{array}{c}0.022 \\
(0.007)\end{array}$ & $\begin{array}{c}0.002 \\
(0.067)\end{array}$ \\
\hline Cause of decline & $\begin{array}{l}-0.346 \\
(0.230)\end{array}$ & $\begin{array}{l}-0.276 \\
(0.227)\end{array}$ \\
\hline Firm size ${ }^{b}$ & $\begin{array}{c}0.292 * * \\
(0.101)\end{array}$ & $\begin{array}{c}0.310^{* *} \\
(0.102)\end{array}$ \\
\hline Industry environment & $\begin{array}{l}-0.021 \\
(0.292)\end{array}$ & $\begin{array}{c}0.023 \\
(0.286)\end{array}$ \\
\hline Consulting firm & $\begin{array}{l}-0.004 \\
(0.019)\end{array}$ & $\begin{array}{c}0.003 \\
(0.019)\end{array}$ \\
\hline Turnaround behavior ${ }^{b}$ & & \\
\hline Shifting balance & & $\begin{array}{l}1.246 * * \\
(0.455)\end{array}$ \\
\hline Simultaneous & & $\begin{array}{c}2.090^{+} \\
(1.074)\end{array}$ \\
\hline Sequential & & $\begin{array}{c}0.450 \\
(0.442)\end{array}$ \\
\hline Others & & $\begin{array}{c}0.532 \\
(0.440)\end{array}$ \\
\hline $\mathrm{R}^{2}$ & 0.130 & 0.197 \\
\hline Adjusted $\mathrm{R}^{2}$ & 0.077 & 0.122 \\
\hline$\Delta \mathrm{R}^{2}$ & & $0.067^{* *}$ \\
\hline
\end{tabular}

Notes:

${ }^{a}$ Values are unstandardized regression coefficients, with standard errors in parentheses.

${ }^{\mathrm{b}}$ Average value of the initial and advanced turnaround stage. Simultaneous behavior ommitted.

${ }^{+} \mathrm{p}<.10 ; * \mathrm{p}<.05 ; * * \mathrm{p}<.01 ; * * * \mathrm{p}<.001$ 
FIGURE 1

Classification of retrenchment and recovery relationships*

Mechanisms

Retrenchment

Recovery

\begin{tabular}{|c|c|c|}
\hline \multirow{2}{*}{ Retrenchment } & Q1. Retrenchment drives out recovery & Q2. Recovery enables retrenchment \\
\hline & $\begin{array}{l}\text { Selected manifestations: } \\
\text { - Retrenchment leads to a mechanistic } \\
\text { shift that fosters further retrenchment, } \\
\text { but hinders strategic change and } \\
\text { recovery } \\
\text { - } \text { Retrenchment exacerbates the climate } \\
\text { and decision-making processes, which } \\
\text { affects recovery negatively. }\end{array}$ & $\begin{array}{l}\text { Selected manifestations: } \\
\text { - } \\
\text { Recovery offers retrenchment activities } \\
\text { strategic direction and prevents resource } \\
\text { losses through retrenchment } \\
\text { - } \quad \text { Recovery mobilizes stakeholder support } \\
\text { and ensures employee commitment to } \\
\text { retrenchment activities }\end{array}$ \\
\hline & Q3. Retrenchment enables recovery & Q4. Recovery drives out retrenchment \\
\hline Recovery & $\begin{array}{l}\text { Selected manifestations: } \\
\text { - } \quad \text { Retrenchment generates resources for } \\
\text { increased experimentation and enables } \\
\text { risk-taking behavior in recovery } \\
\text { - } \quad \text { Retrenchment allows for quick } \\
\text { successes to build confidence and } \\
\text { create the momentum for recovery } \\
\text { moves }\end{array}$ & $\begin{array}{l}\text { Selected manifestations: } \\
\text { - Recovery requires TMT characteristics } \\
\text { that support further recovery, but hinder } \\
\text { concurrent retrenchment } \\
\text { - } \quad \text { Recovery leads to an organic shift that } \\
\text { fosters further recovery, but prevents } \\
\text { concurrent retrenchment }\end{array}$ \\
\hline
\end{tabular}

* Table based on Farjoun (2010) 
FIGURE 2

Framework for hypotheses testing

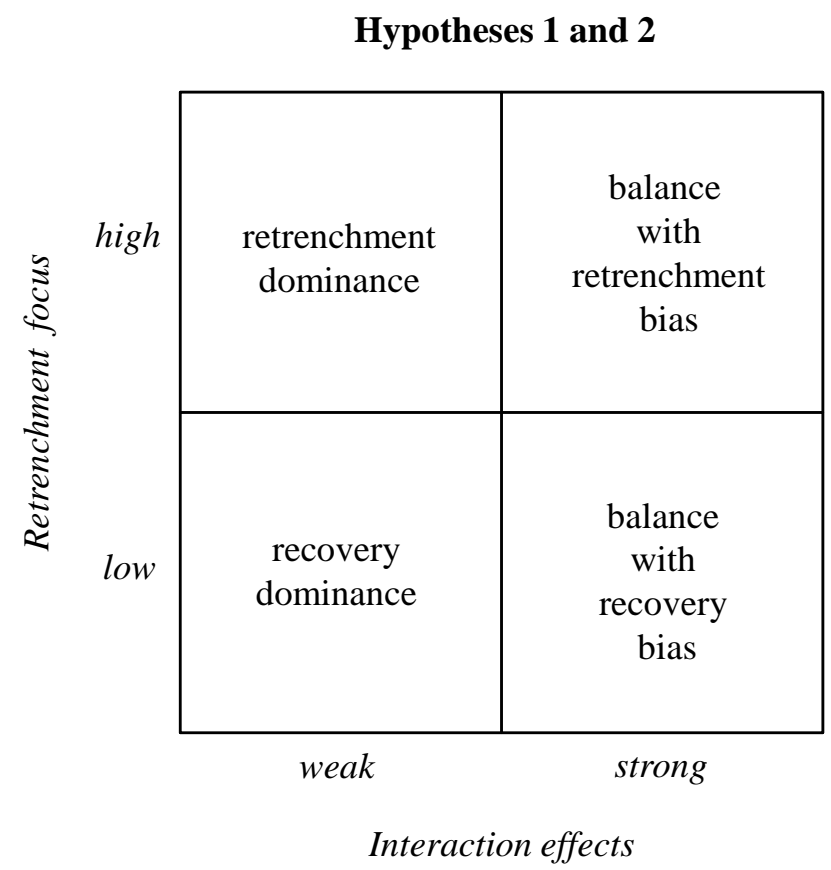

Hypothesis 3

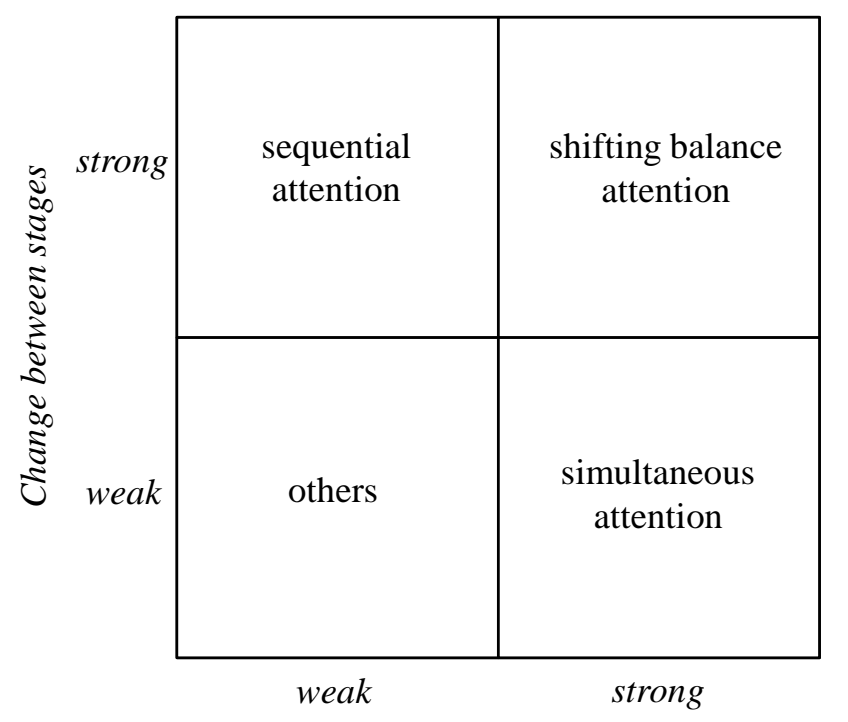

Interrelation score between stages 